\title{
TURISMO GASTRONÓMICO, DENOMINACIONES DE ORIGEN Y DESARROLLO RURAL EN ANDALUCÍA: SITUACIÓN ACTUAL
}

\author{
Genoveva Millán Vázquez de la Torre', Emilio Morales Fernández² y Leonor M. Pérez Naranjo ${ }^{1}$ \\ ${ }^{1}$ Departamento de Gestión y Métodos Cuantitativos. Universidad de Córdoba \\ gmillan@etea.com, Iperez@uco.es \\ 2 Departamento de Organización de Empresas. Universidad Loyola Andalucía \\ emorales@uloyola.es
}

\section{RESUMEN}

Las zonas rurales de Andalucía generalmente concentran su producción en actividades económicas directamente vinculadas con el sector primario, teniendo sus habitantes bajos niveles de ingresos, necesitando obtener rentas adicionales que eleven su nivel de vida. El turismo rural y en especial el gastronómico pueden ser el motor de desarrollo económico y generación de empleo. Este trabajo presenta un análisis del perfil del turista gastronómico en Andalucía y la oferta existente asociada a las Denominaciones de Origen e Indicaciones Geográficas Protegidas, con el objetivo establecer un producto turístico de calidad acorde con la demanda existente, generando una actividad que puede complementar a la agraria, creando riqueza en esas zonas rurales.

Palabras clave: Turismo gastronómico; denominaciones de origen; rutas gastronómicas; desarrollo rural.

\begin{abstract}
Andalusian rural areas generally concentrate their production in economic activities directly related to the primary sector. As the inhabitants of these areas have low levels of income, additional revenues are needed to raise their standard of living. Rural tourism, and especially the gastronomic tourism, may be the engine of economic development and of job creation.
\end{abstract}

Fecha de recepción: junio 2012.

Fecha de aceptación: febrero 2013. 
This paper presents an analysis of the gastronomic tourist profile in Andalusia and the supply linked to Protected Designations of Origin and Protected Geographical Indications, in order to establish a quality tourism product appropriate to the demand. The tourist activity can complement the agricultural activity, generating wealth in these rural areas.

Key words: gastronomic tourism, protected designation of origin, gastronomic routes, rural development.

\section{INTRODUCCIÓN}

El desarrollo económico de las zonas rurales en España aún se basa fundamentalmente en el sector primario, aunque en los últimos años se ha detectado una tendencia en la incorporación de nuevas actividades en estas comarcas, entre las que destaca especialmente el sector turístico, el cual está empezando a reportar a los ciudadanos que habitan en estas áreas unas rentas complementarias adicionales generando un volumen de negocio importante, e implicando, obviamente, la creación de puestos de trabajo.

El turismo como fenómeno a nivel mundial empieza a organizarse a partir de la segunda mitad del siglo XIX, transformándose en el siglo XX (Trigo, 1993) en una actividad de masas (turismo de sol y playa), siendo esta modalidad la principal fuente de riqueza de Andalucía. Sin embargo, en el presente trabajo no se analizará este tipo de turismo, sino el turismo gastronómico como modalidad del turismo rural, definiéndose como «aquella actividad turística realizada en el espacio rural, compuesta por una oferta integrada de ocio, dirigida a una demanda cuya motivación es el contacto con el entorno autóctono, que tiene una interrelación con la sociedad local», (Fuentes, 1995) y que desea conocer los productos gastronómicos de la tierra y sus procesos productivos.

En las últimas décadas, es de sobra conocido el interés que ha despertado en los ciudadanos, tanto nacionales como extranjeros, el turismo desarrollado en zonas rurales, debido a una fuerte atracción por las actividades deportivas, culturales, gastronómicas, etc., motivado por un cambio en diversos factores que han incidido en la modificación de los hábitos y valores del consumidor, como:

- La inversión de la pirámide de población. Los colectivos con mayor estabilidad económica -adultos y de la tercera edad-son más numerosos que en décadas anteriores. Esto beneficia al sector turístico.

- Los hábitos y valores de la población han variado. Actualmente a la población le interesa conseguir y mantener una salud y un cuerpo satisfactorios, y para lograrlo se elige realizar actividades en ambientes naturales.

- La calidad de vida de la población ha mejorado.

- Han incrementado los niveles de renta disponible, y por tanto mayor parte de la renta familiar se puede utilizar para gastos vinculados a vacaciones y viajes.

- Ha aumentado la proporción de tiempo libre.

Todo ello ha contribuido al desarrollo de una importante industria relacionada con el tiempo de descanso, «el turismo». El conocimiento de estos factores y las motivaciones que 
llevan a las personas a realizar turismo gastronómico son las variables necesarias para estimar la demanda, y adoptar todas las medidas oportunas para acomodar la oferta a esas necesidades cambiantes, y no crear desequilibrios entre oferta y demanda, según López (2010) la adaptación a los gustos del turista ya no es una opción, sino una necesidad. En resumidas cuentas, hay que conocer el perfil del consumidor de turismo gastronómico y ofertar un producto a su medida, necesitando una mayor especialización de la oferta, que pueda presentar un producto de calidad creando una imagen turística de la zona. Y para ello es necesario que se cumplan los siguientes parámetros:

- La elaboración de un plan de comercialización, basado en la creación de Centrales de Reservas y puntos de información que faciliten, de este modo, la comunicación de los servicios y productos ofertados.

- La necesidad de formar y reciclar al personal del sector turístico.

- La creación de un sistema de señalización de rutas gastronómicas, almazaras, bodegas, industrias alimentarias, alojamientos, restaurantes, etc.

\section{EL TURISMO COMO AGENTE DE DESARROLLO DE ZONAS RURALES}

El turismo rural conviene considerarlo un instrumento para lograr el desarrollo de regiones donde existe un gran desequilibrio socioeconómico. La Andalucía rural ostenta una elevada tasa de población ocupada en el sector primario. Según datos del Instituto de Estadística de Andalucía (IEA), más de la mitad de los municipios andaluces tienen una población ocupada en el sector agrícola por encima del 25\% del total (SIMA, 2010). Con este porcentaje parece necesario y oportuno diversificar las rentas de la población rural para asegurar el desarrollo y la prosperidad de la zona. Así pues, se propone el turismo rural como actividad generadora de rentas complementarias y elemento distribuidor de la renta.

El turismo rural, además de ser considerado agente de desarrollo económico, presenta un conjunto de características que lo hacen especial. Las más importantes y diferenciadoras, respecto a otros segmentos turísticos, son las siguientes:

1. La actividad turística en zonas rurales puede ser un elemento de estabilización sociodemográfica, al evitar la migración poblacional -éxodo de la población rural- a zonas urbanas, una de las principales dificultades que sufren estas zonas. Asimismo, también puede contribuir a reducir, en cierta manera, las tasas de paro de las zonas urbanas receptoras de las migraciones rurales.

2. El turismo rural goza, entre sus particularidades, de ser un turismo que rompe con la tradicional estacionalidad, típica de este sector, de gran importancia desde el punto de vista económico. El tipo de turismo que nos ocupa (gastronómico), se efectúa con mayor periodicidad, a lo largo de todo el año: fines de semana, puentes, vacaciones de navidades, verano... con una mayor independencia de la climatología que se venga desarrollando. Por tanto, empleo que se cree no tendrá por qué ser temporal, como la mayor parte del generado por el turismo de masas, beneficiando a la población de la zona. 
3. Económicamente el turismo, como es conocido, provoca un efecto multiplicador, en el caso del turismo rural no iba a ser diferente, fomenta el crecimiento de otros sectores económicos y crea puestos de trabajo directa e indirectamente, y de un modo u otro ayudará a redistribuir la renta entre regiones. Estimulara el crecimiento del empleo directamente, destinado a producir servicios de índole turística, y empleo indirectamente, destinado a la obtención de las materias primas utilizadas en la producción de los bienes y servicios consumidos por los turistas.

4. De igual modo, provocará pluriactividad en la población de las zonas rurales, diversificando las rentas obtenidas, disminuyendo la dependencia con el sector primario y reduciendo el riesgo que ello conlleva (Swarbrooke, 1996).

5. Provee, con frecuencia, un incentivo (y parte de la financiación necesaria) para el desarrollo de infraestructuras, lo cual contribuye al crecimiento de otras actividades económicas en las áreas rurales.

En ningún caso se aboga por convertir al turismo en la principal fuente de rentas de las zonas rurales, sino a una contribución de ingresos complementarios para los habitantes de las mismas. Porque si aconteciese, lo contrario conllevaría a una alta probabilidad de saturación del medio rural, y lo que se pretende es fomentar la sostenibilidad del medio ambiente, para generar riqueza y empleo a lo largo del tiempo.

Es necesario tener presente que el desarrollo económico no se debe llevar a cabo a cualquier precio, es preciso ser consciente que una masificación conllevaría a desequilibrios en el medio donde se desarrollaría la actividad económica. Manteniendo y conservando el medio ambiente hay que lograr un desarrollo turístico respetuoso con el entorno natural y cultural que se ve implícito en la conservación del mismo. Para ello, las zonas de interior han de ser conscientes de la oportunidad que ha surgido, al existir un hueco que evidentemente debería ser aprovechado.

Por tanto se hace imprescindible la cooperación, diálogo y coordinación de los diferentes agentes económicos, sociales e instituciones, tanto locales, provinciales, autonómicos y supranacionales. Se precisa igualmente implicar a la sociedad y educarla, es fundamental, organizar y planificar cualquier actividad e iniciativa licita que mediante el fomento turístico pueda generar un florecimiento y una prosperidad económica en la zona, para ello, es imprescindible condicionar el medio ambiente del lugar como atractivo turístico y promover desarrollo estable y sostenido y aumentar el grado de compromiso de los habitantes de la zona en materia de turismo, ya que ellos serán los más beneficiados.

En este trabajo se defiende la tesis de que el turismo rural es intrínsecamente sostenible basándonos en la argumentación anterior, ya que atrae a un número pequeño de visitantes, no hay necesidad de desarrollo extenso de infraestructura, los turistas generalmente están interesados en la cultura local y tradiciones creándose una interacción personal entre ellos y los residentes locales (Bell y Arranz, 2011), pudiendo intercambiar ideas y conocimientos, el turismo puede cumplir su papel como «industria de paz» Rátz y Puczkón(1998), no obstante este desarrollo turístico ocasionará impactos positivos:

- Mejora de los recursos disponibles (como tierra, capital, trabajo, atractivos naturales y culturales) disminuyendo el área agrícola (fuente principal de ingresos). 
- Cambios socio-económicos.

- Contribuye a la protección de la herencia cultural, recuperando las tradiciones y actividades artesanales y permitiendo la conservación del medio ambiente.

- Provee más contacto social para las personas locales y aumenta sus oportunidades de aprender sobre otras culturas.

\section{Y negativos:}

- El turismo en áreas rurales cambia o daña el paisaje natural y los valores naturales y culturales de la zona.

- Reordena la estratificación social.

- Crea presión adicional sobre la comunidad local, cambia sus ritmos de vida, amenaza la privacidad o resulta una presentación no autentica de sus costumbres y tradiciones locales, adaptadas a los deseos de los turistas.

- Aumento del costo de vida.

Por tanto, será necesaria la eficaz y eficiente planificación y gestión de todos los recursos de la región para que sea rentable, no superando su capacidad de carga. Hay autores como (Keane \& Quinn, 1990; Peters, 1997) que dudan de la sostenibilidad del turismo rural, indican que en la mayoría de los destinos turísticos rurales sea viable el turismo como única fuente de ingresos ya que las tasas de ocupación son bajas y con frecuencia la inversión requerida para crear o mejorar los servicios destinados al turismo rural es alta, sobretodo en la inversión que hay que realizar para la gestión medioambiental de los recursos naturales vulnerables, ya que los turistas son atraídos principalmente por las regiones menos desarrolladas industrialmente, lo que las hace particularmente sensibles a la inferencia humana, además, los paisajes agrícolas manejados no siempre satisfacen las expectativas de los turistas que se basan en las imágenes de paisajes rurales tradicionales representados en la literatura turística y en materiales de promoción no acordes a veces con la realidad. Abogan estos investigadores por convertir al turismo rural en una fuente alternativa generadora de ingresos de una región, así como el papel que puede desempeñar en el desarrollo sostenible estará altamente influenciado por el comportamiento de otros sectores económicos (especialmente la agricultura) dependiendo cada zona rural.

Si se desea incrementar el turismo es necesario la adopción de medidas para mejorar la imagen de la zona, fomentar el turismo participativo, en el que los visitantes pueden integrarse y ser participes de tareas y costumbres y modas de vida locales, y el rescate de actividades tradicionales, dará al producto y servicio ofrecido por la zona un grado de diferenciación con el resto de los destinos competidores generando desarrollo económico.

\section{EL TURISMO RURAL EN ANDALUCÍA}

Andalucía tiene un gran potencial de espacios naturales para realizar turismo rural. El $20 \%$ de su territorio está catalogado como protegido, aproximadamente 2,5 millones de hectáreas. Es la comunidad española con más superficie protegida. Esta cuenta con 2 Parques Nacionales, 28 Reservas Naturales, 2 Paisaje Protegido, 40 Monumentos Nacionales, 32 
Parajes Naturales, 5 Reservas Naturales Concertadas, 21 Parques Periurbanos y 24 Parques Naturales, que ocupan el equivalente al $85 \%$ de la superficie total protegida de la Comunidad (Consejería de Medio Ambiente de la Junta de Andalucía, 2011).

Con los recursos naturales que posee la región, hacen que el turismo rural esté adquiriendo una relevancia creciente cada vez mayor, necesitando la aplicación de herramientas estadísticas para identificar la demanda de este segmento turístico. En el año 2010, la demanda de turismo de interior en Andalucía ascendió a 3,42 millones de turistas (INE, 2012)) siendo el principal demandante de turismo rural el mercado nacional (70\%), del cual el 58\% fue turista residente en Andalucía y el 12\% restante, de otras Comunidades Autónomas; frente al 30\% extranjero, donde destacan el turista británico y alemán (10,6\% y 3,8\%, respectivamente). En cuanto al gasto medio diario realizado por estos turistas, en el año 2011 fue de 60,78 euros, un 38\% superior al del año 1999 (figura 1). De esta cantidad, el 85\% del presupuesto se destinó a restauración, alojamiento y a compras.

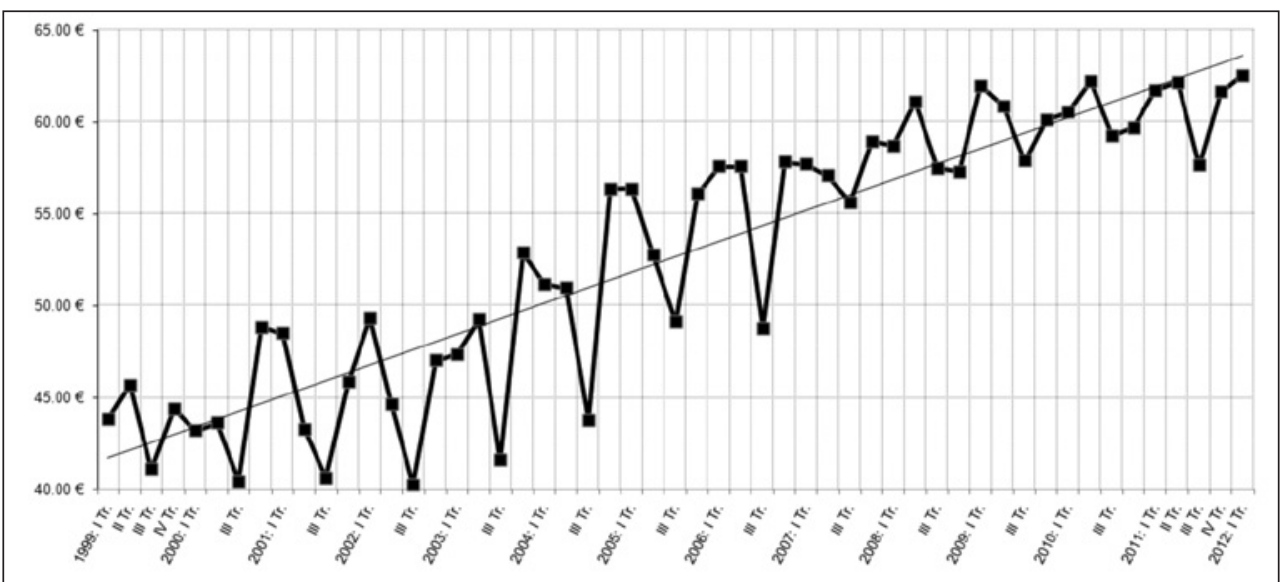

Fuente: Elaboración propia a partir de la Encuesta de Ocupación en alojamientos Turísticos (EOT) del Instituto Nacional de Estadística (INE, 2012).

Dos de los indicadores que sirven para analizar la evolución del turismo rural son: el número de establecimientos de turismo rural abiertos y la estancia media de los viajeros. Al ser variables con una ligera estacionalidad, se realizan comparaciones respecto al mismo periodo de años anteriores. En la figura 2 se observa un repunte en el número de establecimientos hoteleros de turismo rural, el cual ha pasado de 1.250 en enero de 2011 a 1.291 en enero de 2012, teniendo una tendencia creciente desde el año 2004.

En la figura 3 se observa que la estancia media creció de 3,35 días en 2011 a 3,55 en 2012, siendo el mes de agosto el de mayor pernoctaciones medias, con 5,97 días, correspondiendo a uno de los meses donde es mayor el número de personas que tienen descanso estival en España (como se ha mencionado antes, este es el principal mercado de turismo rural). En este sentido, para evitar dicha caída, y en épocas de crisis, sería oportuno orientarse -como 
Figura 2

ESTABLECIMIENTOS DE TURISMO RURAL EN ANDALUCIA (2005-2011)

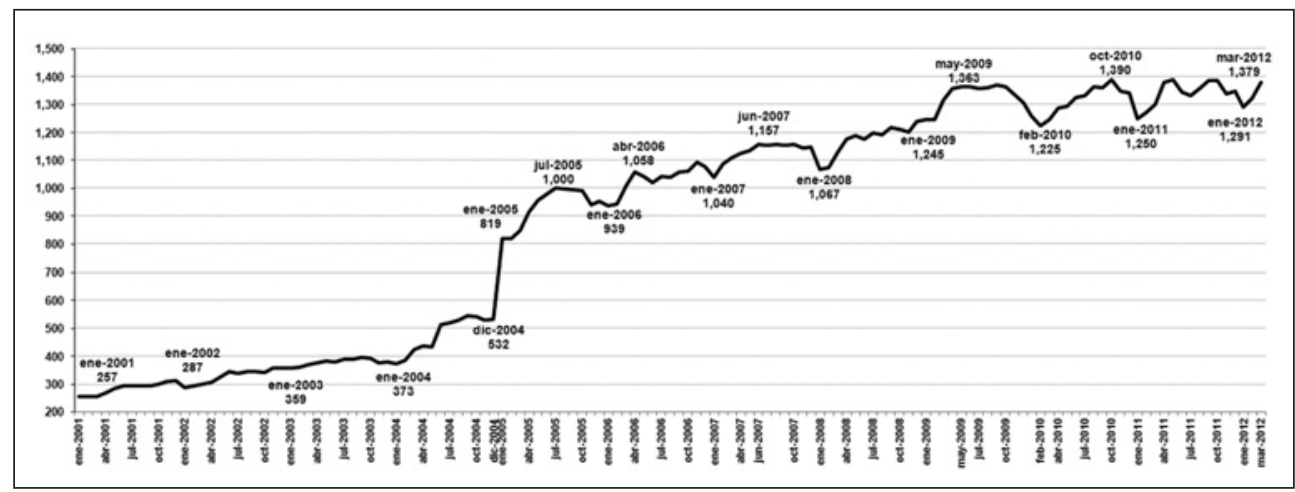

Fuente: Elaboración propia a partir de la EOT del INE (2012).

Figura 3

ESTANCIA MEDIAANUAL Y MENSUAL EN ALOJAMIENTOS DE TURISMO RURAL (2001-2012)

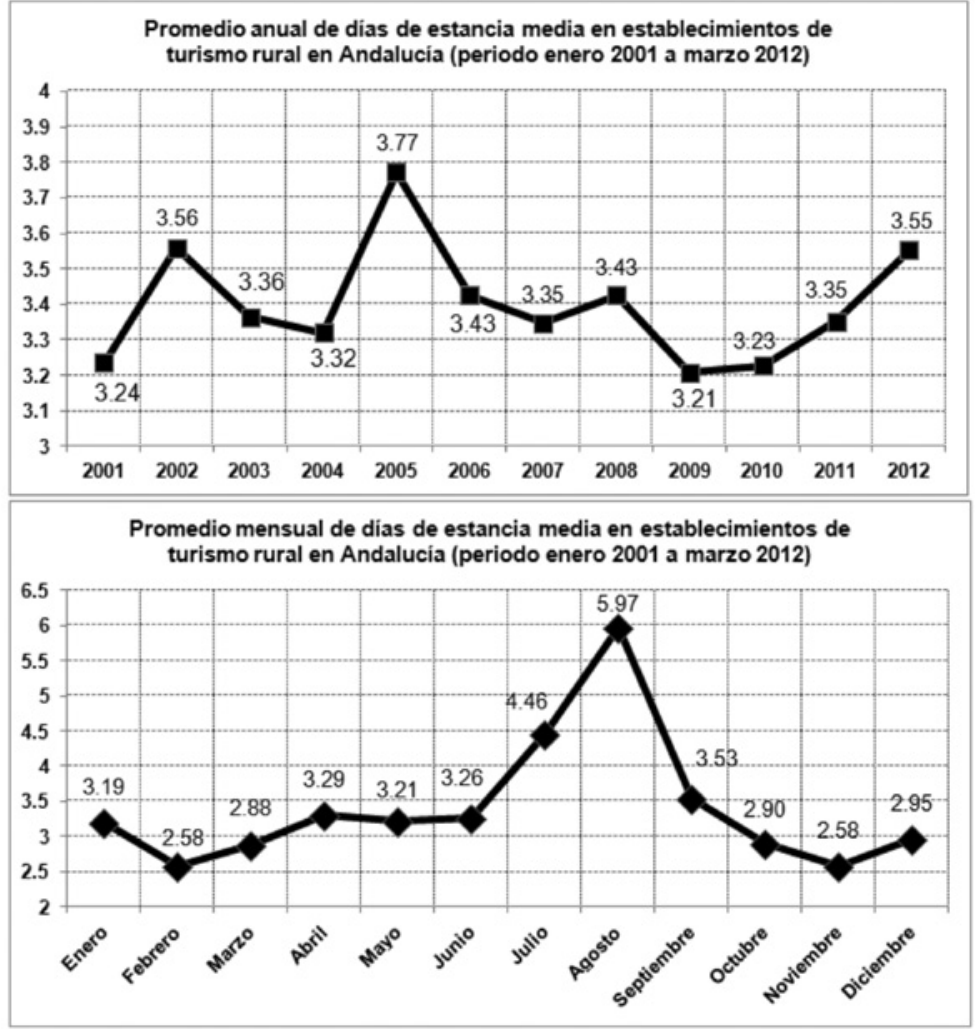

Fuente: Elaboración propia a partir de la EOT del INE (2012). 
indican Pulido y Cárdenas (2011) - al mercado internacional, casi inexistente en muchas de las regiones españolas. Dichos autores abogan por generar una oferta diferencial, sustentada en la personalidad de cada territorio y que responda a segmentos de demanda cada vez más reducidos y especializados, a través de una promoción y comercialización adecuadas.

Analizando el mercado de trabajo en Andalucía, las cifras (Cuadro 1) revelan que el sector servicios aglutinó en 2010 algo más del 74\% de la masa laboral de la región, el 11,7\% de los ocupados (335.407 personas) en actividades del sector turístico.

Cuadro 1

OCUPADOS EN ANDALUCÍA POR SECTORES ECONÓMICOS (MILES)

\begin{tabular}{|c|c|c|c|c|}
\hline \multicolumn{2}{|r|}{ SECTOR } & 2009 & 2010 & Variación anual \\
\hline \multicolumn{2}{|r|}{ Agricultura } & $217,4 \quad(7,4 \%)$ & $230,5 \quad(8,1 \%)$ & $+0,7 \%$ \\
\hline \multicolumn{2}{|r|}{ Industria } & $275,9 \quad(9,5 \%)$ & $259,7 \quad(9,1 \%)$ & $-0,4 \%$ \\
\hline \multicolumn{2}{|c|}{ Construcción } & $284,9 \quad(9,8 \%)$ & $246,7 \quad(8,6 \%)$ & $-1,2 \%$ \\
\hline \multirow{2}{*}{ Servicios } & Industria Turística & $341,1(11,6 \%)$ & $335,4(11,7 \%)$ & $+0,1 \%$ \\
\hline & Resto Servicios & $1.803,9(61,7 \%)$ & $1.787,0(62,5 \%)$ & $+0,8 \%$ \\
\hline \multicolumn{2}{|c|}{ Total ocupados } & $2.923,2$ & $2.859,3$ & $-2,2 \%$ \\
\hline
\end{tabular}

Fuente: Elaboración propia a partir de la Encuesta de Población Activa (EPA) del INE (2012).

De esa cifra total de ocupados en la industria turística, 12.476 pertenecían a actividades relativas al turismo rural (Figura 4), el 52,51\% de estos trabajadores estaban empleados en actividades y servicios de restauración (6.552), el 18,4\% en otras actividades turísticas (2.293), el 17,8\% en alojamientos rurales y el 11,31\% en actividades de transporte , observándose una pérdida de puestos de trabajo de 2009 a 2010, no estando de acorde con la evolución de los establecimientos que están creciendo o del número de pernoctaciones medias las cuales también han aumentado. Cabría preguntarse: ¿trabajan más horas los trabajadores de turismo rural? ¿o existe más economía sumergida?

Figura 4

OCUPADOS EN ACTIVIDADES RELACIONADAS AL TURISMO RURAL (AÑO 2010)

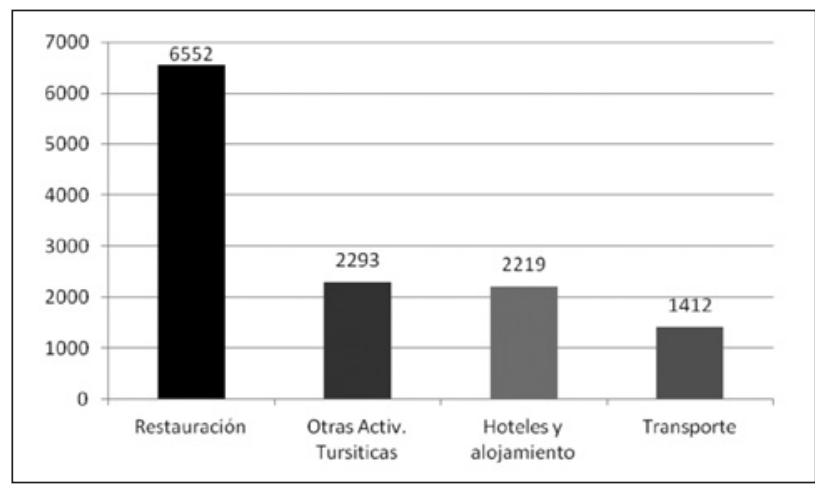

Fuente: Elaboración propia a partir de la EPA del INE (2012). 
Observando la situación actual del mercado turístico (el cual se ha visto afectado en parte por la crisis) se hace necesario potenciar las singularidades de la zona y unir sinergias, con el fin de ofrecer un producto diferenciado, que ayude a posicionarse como referente turístico. Al considerar al turismo rural como un conjunto de actividades recreativas realizadas en zonas rurales y basadas en elementos de cultura rural, se entiende que este segmento turístico abarca dentro de sus servicios y productos: practicar deportes, disfrutar de la naturaleza, conocer los productos de la zona (café, quesos, vinos, setas, aceites...) o tan solo disfrutar de la tranquilidad que ofrece el medio rural. Una amplia gama de productos complementarios durante todo el año incrementará la demanda de turistas que pueden visitar dichas zonas en cualquier época, generando empleos más estables.

La gastronomía y los productos alimenticios de la tierra se convierten por tanto, en los recursos esenciales del turismo gastronómico en el ámbito rural, siendo las rutas alimentarías el principal instrumento turístico en donde convergen las potencialidades y sinergias de las zonas rurales.

\section{EL TURISMO GASTRONÓMICO COMO MODALIDAD DE TURISMO RURAL}

El cambio del papel económico y social de las zonas rurales ha supuesto una evolución de la tradicional función productora de productos alimenticios a la reestructuración de la estructura productiva, ofreciendo nuevas oportunidades laborales para la población. En este contexto, las diferentes modalidades del turismo rural han supuesto un medio accesorio para solucionar los principales problemas y desafíos que presentan las regiones de interior. El turismo no debe ser la principal fuente de rentas de las zonas rurales, pero si una fuente generadora de ingresos complementarios para los habitantes rurales.

Los cambios que se están produciendo en los últimos años en la actividad turística están posibilitando la aparición de nuevos destinos que, lejos de los tradicionales de sol y playa, generan vías complementarias de riqueza y creación de empleo. Así, junto con destinos de interior ya clásicos, están surgiendo otros productos turísticos que dan respuesta a determinados segmentos de la población. Fruto de estas nuevas demandas se encuentra la creación de rutas turísticas, entre las que destacan las rutas alimentarias, surgiendo un nuevo concepto de turismo, el gastronómico, entendido como el desplazamiento de visitantes, tanto turistas como excursionistas, cuyo motivo principal es la gastronomía, que involucra prácticas que van desde el mero desplazamiento del lugar de residencia hacia un restaurante donde degustar un plato o conocer el proceso de elaboración del mismo (Oliveira, 2011). En los últimos años esta modalidad de turismo, está teniendo cada vez una importancia mayor dentro del sector turístico (Espejel et al. 2011).

Las nuevas tendencias en los hábitos de consumo, con un interés social creciente en productos de calidad, diferenciados y adaptados a las nuevas necesidades de grupos y segmentos del mercado diferentes. Este incremento en el consumo de productos diferenciados y de calidad en el ámbito agroalimentario ha propiciado el desarrollo de indicadores geográficos de procedencia, particularmente las Denominaciones de Origen Protegidas (D.O.P.). Estas se definen a partir del origen geográfico de los productos agroalimentarios, integrando la tradición y especialización en la elaboración con criterios de calidad garantizada y características diferenciadas a través de una estricta reglamentación y mecanismos de control sobre su producción (Márquez y Hernández, 2001). 
Blanco y Riveros (2004) entienden que una ruta gastronómica o alimentaria es un elemento clave del turismo gastronómico como modalidad de turismo rural y promueve nuevas actividades económicas para mantener y mejorar las condiciones de vida de la población rural. El principal objetivo de una ruta es lograr que el producto en el que se fundamenta integre la mayor cantidad de actores socioeconómicos de la zona, generando más empleo local y diversificando la oferta existente. No obstante, uno de los principales retos es evitar convertir a esta modalidad de turismo en la principal fuente de rentas de la zona rural, sino en una fuente complementaria de ingresos.

Cada ruta alimentaria ofrece placeres y actividades relacionadas con sus elementos distintivos y se organiza para consolidar la cultura productiva regional, revalorizar los productos agroalimentarios de la zona y dinamizar las economías regionales a través de la promoción de sus productos, consiguiendo un desarrollo alternativo (Everett y Aitchison, 2008).

En el turismo gastronómico los productos alimenticios y las especialidades culinarias se convierten en vehículo de acercamiento cultural en la medida en que se configuran como elementos identificadores de pueblos y territorios (Feo, 2005). Asimismo, Montoya (2003) argumenta que la recuperación de la gastronomía tradicional de las zonas rurales y su incorporación a la oferta turística enriquece los destinos turísticos de interior y mantiene vivo el legado cultural. Por otro lado, Armesto y Gómez (2004) establecen que los productos agroalimentarios se configuran como recursos turísticos gastronómicos que posibilitan el desarrollo del turismo y, al mismo tiempo, el turismo se convierte en herramienta para la promoción y comercialización de los productos agroalimentarios de calidad.

A partir de todas estas características complementarias, las rutas alimentarías pueden ser consideradas como itinerarios que permiten reconocer y disfrutar, de forma organizada, los procesos productivos agropecuarios e industriales y la degustación de la cocina regional, expresiones de la identidad cultural de las zonas rurales. Suelen estar organizadas en torno a productos clave que las caracterizan y les otorgan frecuentemente su denominación. Barrera (2006) las clasifica en:

- Rutas gastronómicas por productos, organizadas en un producto determinado (queso, aceite, vino, etc.).

- Rutas gastronómicas por plato, sustentadas en especialidades culinarias o platos preparados.

- Rutas étnico-gastronómicas, fundamentadas en tradiciones culinarias de pueblos emigrantes.

Las rutas alimentarias ofrecen a los turistas placeres y actividades específicas y variadas asociadas a sus productos distintivos tales como visitas a establecimientos y fábricas para observar el proceso de elaboración y disfrutar de degustaciones de los productos, historias sobre la evolución de los productos, etc. Las rutas gastronómicas también sirven para promocionar los productos típicos de la zona, las marcas alimenticias asociadas y los lugares que presentan una relación especial con el producto, proporcionando un valor añadido al servicio/producto ofrecido al consumidor turístico. La promoción del patrimonio gastronómico y culinario no solo incluye el consumo in situ, a través de los restaurantes de la zona que ofrecen platos tradicionales con productos de la zona, sino que 
también facilita la adquisición de los productos como souvenir, aumentando así las rentas obtenidas y mejorando el posicionamiento del producto alimentario en el mercado.

Por otro lado, el reconocimiento administrativo de la calidad superior en un producto agroalimentario en Europa se fundamenta en la autorización administrativa a nivel nacional de Denominaciones de Origen e Indicaciones Geográficas Protegidas (D.O.P. e I.G.P.). La existencia de estas organizaciones se fundamenta en las características propias y diferenciales debidas al medio geográfico en el que se producen las materias primas y elaboran los productos, así como a la influencia del factor humano que participa en las mismas. Las rutas alimentarías más afamadas recorren circuitos de productos vinculados.

En España existen 186 Denominaciones de Origen Protegidas, de las cuales el 46\% corresponden a un único producto, el vino. El número de Indicaciones Geográficas Protegidas es menor (132) pero significativo (Cuadro 2). Andalucía, con 29 D.O.P. (15,6\% del nacional) y 26 I.G.P. (19,7\% del nacional), es una de las regiones españolas con más cantidad de productos de calidad avalados por este sistema de certificación.

Cuadro 2

DISTRIBUCIÓN DE PRODUCTOS AGROALIMENTARIOS, VINOS Y BEBIDAS ESPIRITUOSAS CON D.O.P. E I.G.P. EN ESPAÑA Y ANDALUCÍA (ACTUALIZADO A MAYO 2012)

\begin{tabular}{|l|r|r|r|r|}
\hline \multirow{2}{*}{ PRODUCTOS AGROALIMENTARIOS } & \multicolumn{2}{|c|}{ D.O.P. en } & \multicolumn{2}{c|}{ I.G.P. en } \\
\cline { 2 - 5 } & España & Andalucía & España & Andalucía \\
\hline Carnes frescas & - & - & 19 & 1 \\
\hline Productos cárnicos & 6 & 2 & 9 & 1 \\
\hline Quesos & 27 & - & 2 & - \\
\hline Otros productos de origen animal (miel) & 3 & 1 & 1 & 1 \\
\hline Aceites y grasas (31 aceites y 2 mantequillas) & 31 & 12 & 1 & 2 \\
\hline Frutas, hortalizas y cereales frescos y transformados & 23 & 3 & 35 & 2 \\
\hline $\begin{array}{l}\text { Pescados, moluscos y crustáceos frescos y productos } \\
\text { derivados }\end{array}$ & 1 & - & 2 & - \\
\hline $\begin{array}{l}\text { Otros productos del Anexo I del Tratado (azafrán, } \\
\text { pimentón, chufa, avellana, vinagre, sidra) }\end{array}$ & 9 & 3 & - & 2 \\
\hline $\begin{array}{l}\text { Productos de panadería, pastelería, repostería y galle- } \\
\text { tería }\end{array}$ & - & - & 14 & $\mathbf{9}$ \\
\hline $\begin{array}{l}\text { TOTAL D.O.P. e I.G.P. de PRODUCTOS AGRO- } \\
\text { ALIMENTARIOS }\end{array}$ & $\mathbf{1 0 0}$ & $\mathbf{2 1}$ & $\mathbf{8 3}$ & - \\
\hline Vinos con Denominación de Origen (DO) & 63 & 6 & - & - \\
\hline Vinos con Denom. de Origen Calificada (DO Ca) & 2 & - & - & - \\
\hline Vinos de Calidad con Indicación Geográfica (VC) & 10 & 2 & - & - \\
\hline Vinos de Pago (VP) & 11 & - & - & $\mathbf{1}$ \\
\hline Vinos con Indicación Geográfica (IG) & - & - & 43 & $\mathbf{1 6}$ \\
\hline TOTAL D.O.P. e I.G.P. de VINOS & $\mathbf{8 6}$ & $\mathbf{8}$ & $\mathbf{4 3}$ & $\mathbf{1 6}$ \\
\hline Bebidas Espirituosas con I.G. & $\mathbf{1 8 6}$ & $\mathbf{2 9}$ & $\mathbf{1 3 2}$ & $\mathbf{2 6}$ \\
\hline TOTAL D.O.P. e I.G.P. & & & & \\
\hline
\end{tabular}

Fuente: Elaboración propia a partir de información del Ministerio de Agricultura, Alimentación y Medio Ambiente y de la Comisión Europea, Dirección General de Agricultura y Desarrollo Rural, Bases de Datos DOOR y E-BACCHUS (2012). 
Figura 5

IMPORTANCIA DE LOS PRODUCTOS AGROALIMENTARIOS AMPARADOS POR D.O.P. E I.G.P. EN VALOR ECONÓMICO (AÑO 2010)

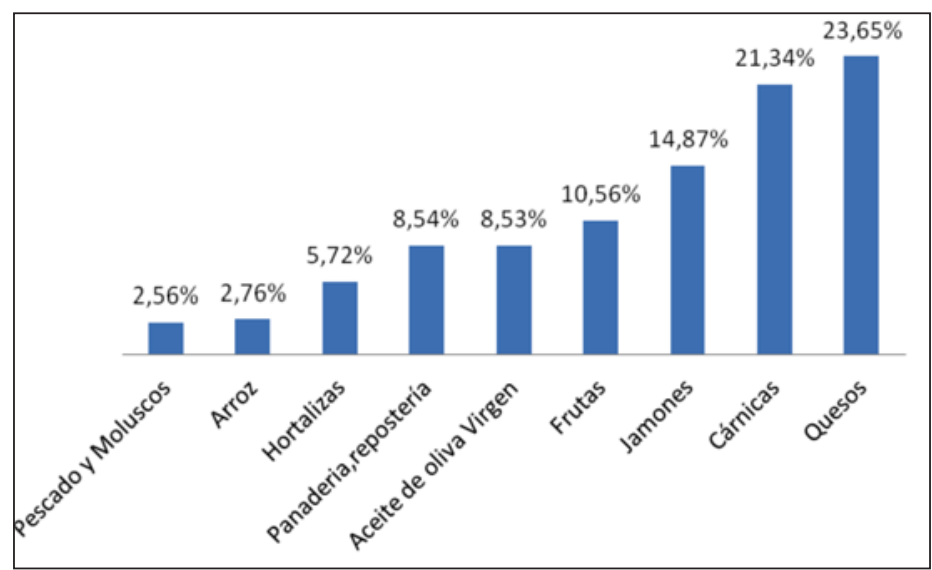

Fuente: Elaboración propia a partir información Ministerio de Agricultura, Alimentación y Medio Ambiente (2012).

Figura 6

EVOLUCIÓN DE LA FACTURACIÓN Y NÚMERO DE D.O.P. E I.G.P. ESPAÑOLAS (1992-2010)

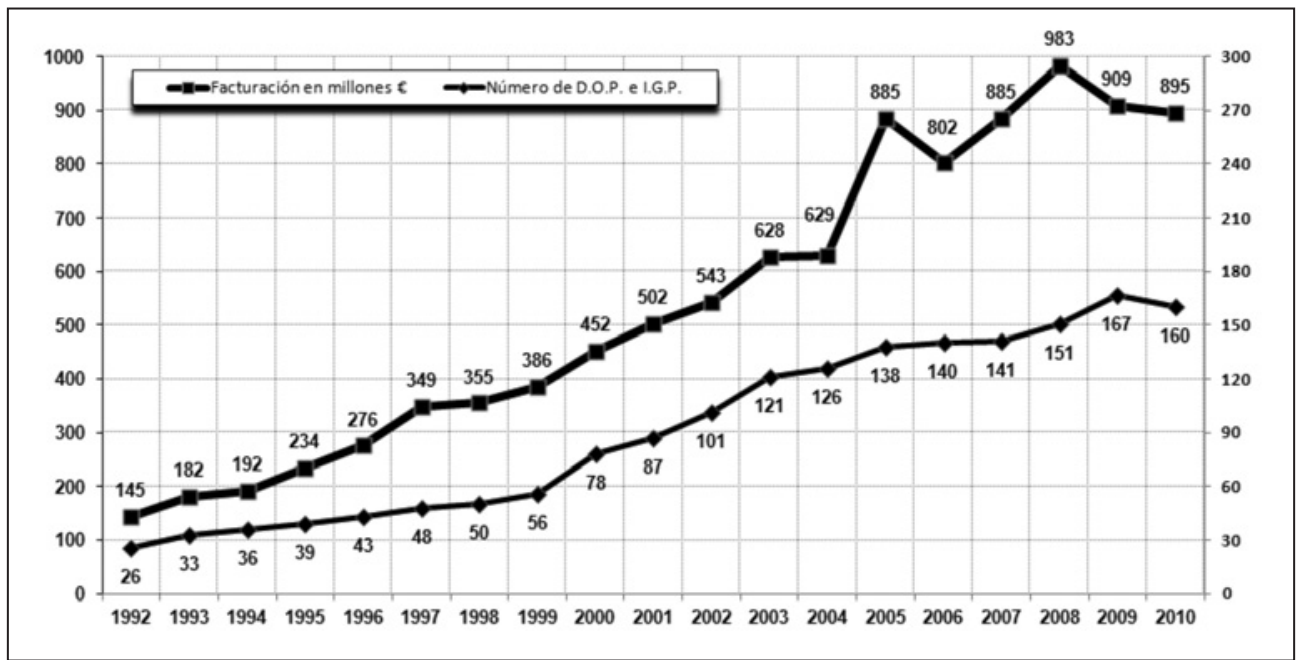

Fuente: Elaboración propia a partir información Ministerio de Agricultura, Alimentación y Medio Ambiente (2012).

Desde el punto de vista económico (Figura 5), el producto agroalimentario más relevante es el queso, que supone el 23,65\% del valor económico total de las D.O.P. e I.G.P. españolas. Le siguen los productos cárnicos (21,34\%), jamones $(14,87 \%)$, frutas $(10,56 \%)$, panadería-repostería y aceite de oliva virgen (8,54\% cada uno). Estas estadísticas del 
Ministerio de Agricultura, Alimentación y Medio Ambiente se refieren específicamente a productos agroalimentarios, no incluyendo al vino, producto con mayor número de denominaciones. Sin embargo, desde la óptica turística el vino es de los productos más conocidos, más apreciados por los turistas gastronómicos y el que posee mayor potencial de desarrollo en este sector.

El número de D.O.P. e I.P.G. ha presentado durante los últimos años un incremento similar al incremento del valor económico (Figura 6), ofreciendo una gran oferta de productos que pueden ser degustados y procesos de elaboración que pueden ser visitados por el turista gastronómico.

También se observa una evolución importante en el valor económico que supone la comercialización de productos agroalimentarios asociados a las D.O.P. e I.G.P. Este se ha multiplicado por 6 en los últimos 18 años, pasando de 145 millones de euros en 1992 a 895 millones de euros en el año 2010. No obstante, en 2010 se produjo un retroceso de casi el $10 \%$ respecto al año 2008, donde se alcanzó una cifra cercana a los 1.000 millones de euros. Esta pérdida económica puede ser compensada, e incluso aumentada, si los empresarios asociados a las denominaciones diseñan estrategias de comercialización apropiadas y sinérgicas con el turismo gastronómico asociados al producto agroalimentario de referencia, tesis que defendemos en esta investigación.

\section{LAS RUTAS GASTRONÓMICAS ASOCIADAS A LAS D.O.P. E I.G.P. DE ANDALUCÍA}

Dentro del turismo rural se puede ubicar el turismo gastronómico, que incluye las rutas gastronómicas, basadas en el conocimiento y disfrute de productos alimenticios, así como de la cultura regional y que consisten en recorridos por carretera y caminos donde se combinan el disfrutar de la gastronomía, belleza paisajística, atractivos históricos y culturales (González, 2011). Por tanto, las rutas gastronómicas son itinerarios asociados a un producto o plato típico de la zona, dentro de una Denominación de Origen conocida.

De las más de 318 D.O.P. e I.G.P. que existen en España, en Andalucía se encuentran ubicadas 54, siendo esta la región española con mayor número, seguida por Castilla-La Mancha y Cataluña con 32, y Castilla y León y Galicia con 30. En Andalucía, las D.O.P. e I.G.P. más destacadas y conocidas por el turista son las del aceite y del vino, debido al desarrollo del vínculo entre producto agroalimentario, D.O.P o I.G.P. y rutas gastronómicas. Sin embargo, existen productos, como las pasas o la miel, que tienen distintivo de calidad pero no ha surgido todavía en los turistas el deseo de conocer el proceso productivo ni la degustación «in situ», al no existir un proceso de elaboración mostrado al turista como en el vino, donde los enoturistas visitan una bodega y pueden apreciar la etapa de maduración de los distintos caldos.

En el cuadro 3 aparecen reflejadas las 29 D.O.P. y 26 I.G.P. ubicadas en territorio andaluz, así como el producto y las provincias concretas dónde se encuentran.

Desde el punto de vista turístico son más conocidas las D.O.P e I.G.P. del vino, pues son las más visitadas por el turista, pero desde el punto de vista económico y en número son más importantes las del aceite, seguidas con gran diferencia del resto de productos. A continuación se analizarán las más relevantes respecto al sector turístico. 


\section{El enoturismo (el turismo del vino)}

La región de Andalucía tiene una tradición milenaria en el cultivo de la vid y en la elaboración de vinos, que han gozado de gran prestigio y fama en todo el mundo. El sector vitivinícola andaluz se orienta hacia la producción de vinos de calidad, con más del $70 \%$ de sus viñedos amparados por alguna de las 6 D.O.P. o las 2 indicaciones geográficas establecidas en la región (véase figura 7), siendo la más conocida y visitada por los turistas la de Jerez y Manzanilla de Sanlúcar de Barrameda (más de 150.000 turistas por año), seguida de Montilla Moriles, que es la Denominación que tiene más viticultores inscritos y bodegas asociadas a la D.O.P.

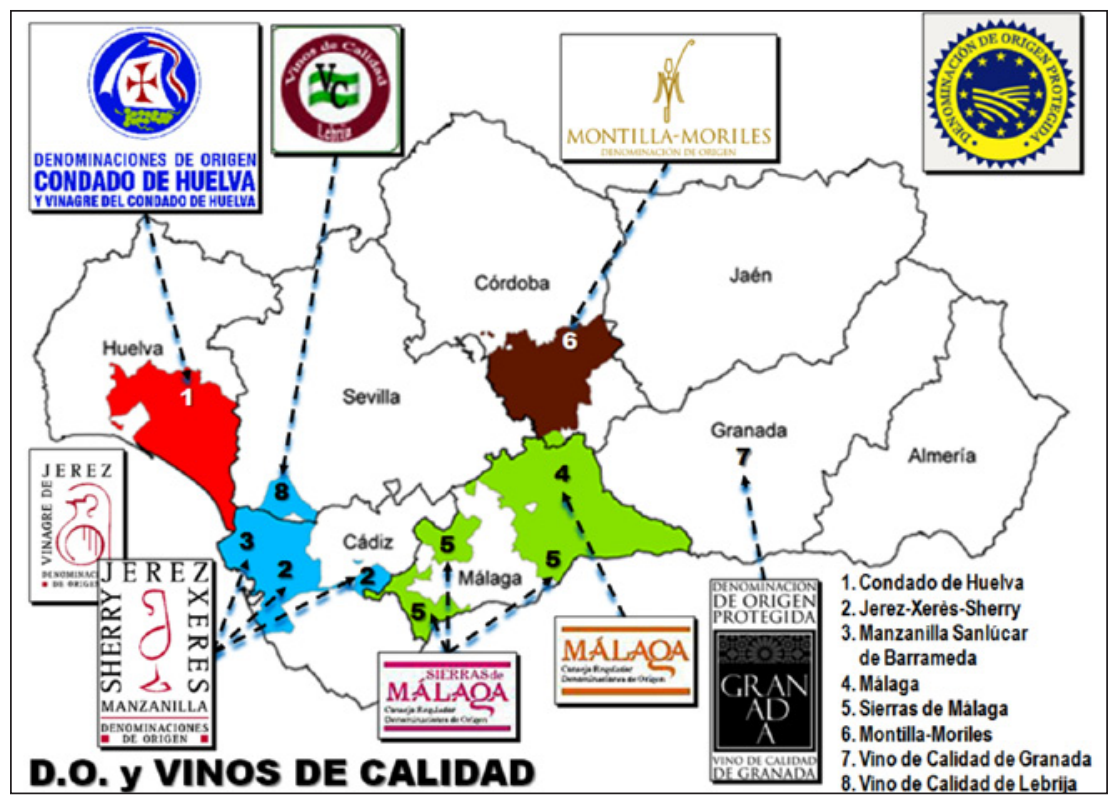

Fuente: Elaboración propia a partir de información del Ministerio de Agricultura, Alimentación y Medio Ambiente y Consejería de Agricultura y Pesca de la Junta Andalucía (2012).

La definición y conceptualización del término enoturismo no es uniforme, ya que se puede analizar desde diferentes ópticas, como la perspectiva del marketing o la motivación de los viajeros. Por ello, y siguiendo a Getz y Brown (2006), el enoturismo es simultáneamente un comportamiento del consumidor, una estrategia para desarrollar el área geográfica y el mercado del vino de dicha zona, y una oportunidad de promoción de la bodegas para vender sus productos directamente a los consumidores. Los recientes estudios en torno al tema del turismo del vino sugieren y promueven la idea de que la comida y el vino pueden ser, y a menudo son, el principal motivo para viajar a una determinada región, y no ser necesariamente una segunda actividad del viaje. 
La importancia que ha adquirido en los últimos años el enoturismo en diferentes partes del mundo está suficientemente documentada en países tales como Chile (Egan y Bell, 2002), Hungría (Szivas, 1999), Estados Unidos (Rasch y Gretzel, 2008), Nueva Zelanda (Beverland, 1988), Sudáfrica (Bruwer, 2003) o incluso España (Gilbert, 1992). Concretamente en España, junto con el estudio anteriormente señalado donde se analiza la importancia que ya empezó teniendo el turismo del vino a principios de la década de los noventa del siglo pasado en la zona de La Rioja, recientemente también se han abordado en diferentes estudios científicos otras zonas vinícolas, entre los que destacamos los de Valencia (Clemente et al., 2010), el Priorato (Armesto y Gómez, 2004) o Montilla-Moriles (Millán y Melián, 2010), donde se aborda cómo el desarrollo de este producto turístico, gestionado por pequeñas y medianas empresas (muchas de ellas cooperativas) puede servir de complemento a otras actividades en las zonas rurales, generando riqueza y creando puestos de trabajo. Elías (2006) describe al enoturismo como los viajes y estancias dirigidas al conocimiento de los paisajes, las labores y los espacios de la elaboración del vino, y a las actividades que acrecientan su conocimiento y adquisición y que pueden generar desarrollo en las diversas zonas vinícolas.

\section{El oleoturismo (el turismo del aceite)}

El olivar ocupa el 19\% de la superficie cultivable en Andalucía. El sector olivarero es un eje económico fundamental para la comunidad. Aporta un gran valor paisajístico y medioambiental (el bosque de olivar) ofreciendo un lugar privilegiado: historia, tradiciones, paisaje y gastronomía, que están impregnados del legado del aceite de oliva. Andalucía puede ofrecer un producto turístico especializado de calidad, con un valor añadido, la ruta del olivo, a través de la cual se promocionará un producto de calidad y se aprovecharán todos los recursos disponibles para ofrecer un servicio/ producto turístico diferenciado.

Visitas a almazaras, catas de aceite, desayunos molineros,... visitas turísticas guiadas aprovechando los recursos locales asociados a la producción del aceite de oliva. Se precisan de medidas concretas de apoyo a ambos sectores, con el fin de conseguir una simbiosis entre el producto gastronómico y el turismo que conlleve al desarrollo socioeconómico de las zonas olivareras.

El aceite de oliva es un producto característico de los países mediterráneos, que ha generado una cultura del olivo: paisajes, tradiciones, forma de vida...que posibilita un nuevo segmento de mercado para dar respuesta a la demanda originada alrededor de este producto alimenticio. En este caso, el oleoturismo posibilitaría que las cooperativas/empresas comercializaran sus productos no solo por los canales normales de distribución, sino que desde el punto de elaboración y cultivo se puede ofertar un producto/servicio turístico con valor añadido, que elevaría sin duda alguna las ventas y la imagen del aceite. Desde una perspectiva eminentemente agrícola, España está considerada como el primer productor mundial de aceite de oliva (aproximadamente el 50\% del total anual). El olivar ocupa una superficie de unos dos millones y medio de hectáreas (más o menos el 25\% de la superficie mundial), con un cultivo de 308 millones de olivos. La región de Andalucía cuenta con una superficie de 1.480.162 ha y concentra el $61,1 \%$ del cultivo del olivo español, seguida a distancia por la región Centro (13,7\% del cultivo), Extremadura (11\% del cultivo), zona del Ebro $(7,4 \%)$ y zona Levante $(6,8 \%)$. 


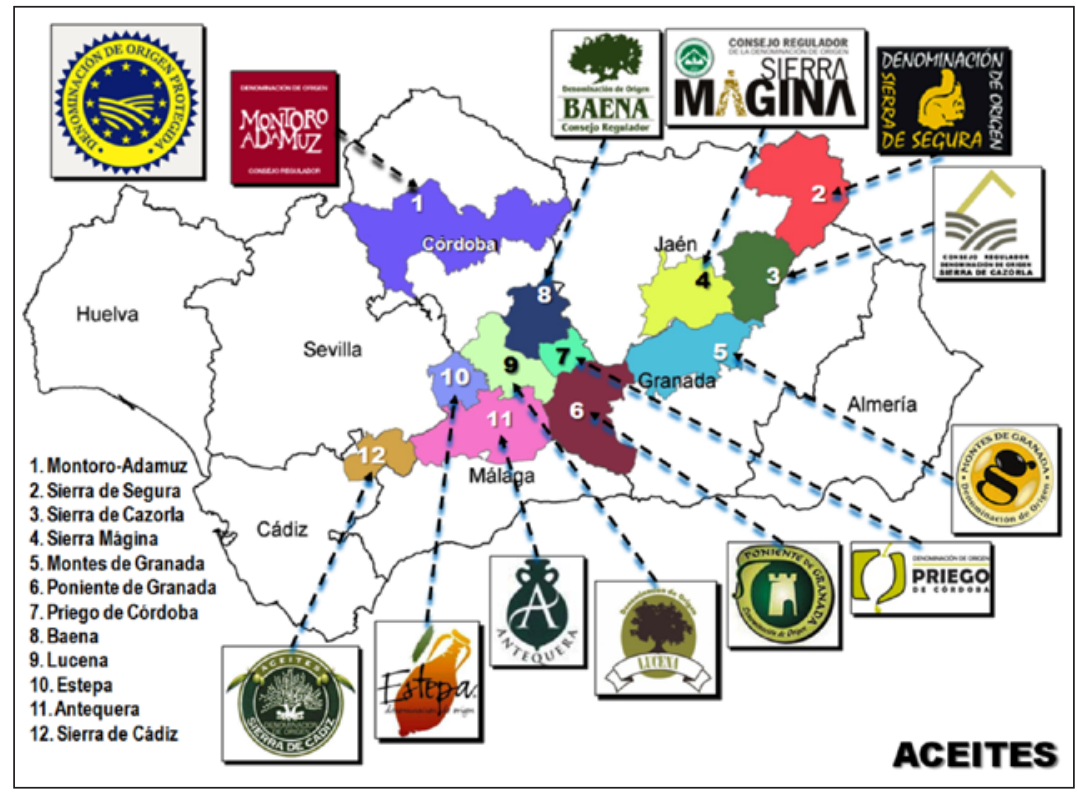

Fuente: Elaboración propia a partir de información del Ministerio de Agricultura, Alimentación y Medio Ambiente (2012).

En la figura 8 se muestran las distintas D.O.P. de aceite de oliva en Andalucía. En España existen 29 denominaciones de origen de aceite de oliva virgen y extra, de las cuales 12 se encuentran ubicadas en la región de Andalucía, con aproximadamente el $41 \%$ de las D.O. de España inscritas en ese producto.

No obstante, Andalucía tiene otras denominaciones conocidas por la calidad de sus productos, como la del jamón Ibérico, donde miles de turistas anuales visitan las ferias y festivales que se organizan en torno al mismo; u otras relacionadas con productos de panadería y bollería como las I.G.P. del mantecado y mazapán, que reciben numerosos grupos de turistas en otoño y navidad, fechas típicas de estos dulces de gran tradición en la Comunidad.

Dado el potencial gastronómico de la Comunidad Andaluza se hace necesario estudiar la oferta y demanda de turismo gastronómico generador de desarrollo en determinadas áreas, especialmente las agrícolas.

\section{METODOLOGÍA DE LA INVESTIGACIÓN Y RESULTADOS}

El objetivo de esta investigación es dar a conocer el perfil del turista y la oferta de turismo gastronómico en Andalucía asociada a las D.O.P. e I.G.P., tomando como referencia los cuatro productos gastronómicos más relevantes: vino, aceite, jamón y productos de bollería, por ser los que están más orientados como comercialización de productos turísticos con sus rutas gastronómicas correspondientes (26 D.O.P. y 20 I.G.P. población de partida de la investigación). 
Cuadro 4

FICHA TÉCNICA DE LAS ENCUESTAS

\begin{tabular}{|l|l|l|}
\cline { 2 - 3 } \multicolumn{1}{c|}{} & \multicolumn{1}{c|}{ Encuestas de oferta } & \multicolumn{1}{c|}{ Encuestas de demanda } \\
\hline Población & $\begin{array}{l}\text { Empresas que forman } \\
\text { parte de la ruta alimentaria } \\
\text { perteneciente a la D.O.P. e } \\
\text { I.G.P. de Andalucía }\end{array}$ & $\begin{array}{l}\text { Turistas de ambos sexos } \\
\text { mayores de 18 años que } \\
\text { visitaron la D.O.P e I.G.P. } \\
\text { Andalucía }\end{array}$ \\
\hline Tamaño muestral & 126 encuestas válidas & 1.009 encuestas válidas \\
\hline Error muestral & $\pm 4,27 \%$ & $\pm 3,89 \%$ \\
\hline Nivel de confianza & $95 \% ; \mathrm{p}=\mathrm{q}=0,5$ & $95 \% ; \mathrm{p}=\mathrm{q}=0,5$ \\
\hline Fecha del trabajo de campo & $\begin{array}{l}\text { septiembre } 2009 \text { a } \\
\text { octubre 2010 }\end{array}$ & $\begin{array}{l}\text { septiembre 2009 a octubre } \\
2010\end{array}$ \\
\hline
\end{tabular}

El núcleo central de esta investigación se basa en dos cuestionarios:

1. Encuesta de Oferta: Dirigida al análisis de cada una de las empresas que forman parte de la denominaciones de origen (almazaras, bodegas, empresas cárnicas y de fabricación de bollería, restaurantes, hoteles, tiendas) que forman parte de la ruta alimentaria correspondiente a las D.O.P. e I.G.P. de Andalucía y a todas aquellas instituciones a través de las cuales se da a conocer el aceite de oliva virgen extra, el vino, jamón, mantecados, etc. con el fin de conocer la oferta turística existente en este campo. Esta encuesta integra 25 preguntas agrupadas en tres bloques (personal-producción, implicación en la ruta gastronómica, acciones encaminadas a fomentar el turismo).

2. Encuesta de Demanda. Dirigida al turista que se acerca a la zona a conocer el proceso productivo, los olivos milenarios, el aceite virgen extra, bodegas, museos del vino, festivales del jamón, museo del mazapán etc. Pretende analizar el perfil socioeconómico de la demanda turística efectiva. El cuestionario contiene 35 preguntas agrupadas en 6 bloques (perfil socio demográfico, perfil económico, perfil del potencial turista, motivación del viaje, características del viaje y valoraciones y opiniones sobre la ruta alimentaria).

\section{Resultados demanda}

\section{Características socioeconómicas del turista gastronómico}

El perfil del turista gastronómico en función de la muestra encuestada sería: de sexo masculino (54\%), con una edad en el intervalo de entre 50 y 59 años (algo más del 40\%), con estudios (77\%), con una renta media entre 1.500 y 2.000 euros. En este apartado existe una diferencia significativa entre el nivel de renta del enoturista y los restantes turistas gastronómicos (oleoturismo, turismo del jamón y de bollería) (Kruskal-Wallis: Sig. asintót. = 0,009). El enoturista suele tener mayor poder adquisitivo. Un $32 \%$ de los enoturistas tiene una renta mensual superior a $2.500 €$, mientras que tan sólo un $5 \%$ de los turistas gastronómicos alcanza ese nivel de renta. Respecto a la dedicación profesional, el 
$20 \%$ de ellos son empleados por cuenta ajena, siendo muy pequeño el porcentaje de estudiantes $(7 \%)$. En referencia al estado civil, la mayoría de los turistas están casados (53\%, frente al $28 \%$ de solteros).

En cuanto a la motivación que les impulso a realizar turismo (figura 9A), destaca la visita a las bodegas, almazaras o fabricas de panadería y bollería, para conocer el proceso de fabricación y la cata de los productos $(47 \%)$, seguida por el interés de la gastronomía y los platos culinarios típicos de la zona (29\%). Está más alejado el precio (7\%), pues el turismo gastronómico sigue siendo todavía más barato que el de sol y playa, principalmente la restauración y alojamientos, que al estar en zonas rurales son más baratos.

Respecto a la elección del destino turístico, ¿por qué escogieron rutas gastronómicas andaluzas? Destaca el elevado porcentaje (48\%) de recomendaciones de amigos y familiares, de ahí que el turismo sea principalmente de la Comunidad. Prima la publicidad «boca a oreja» frente a anuncios en medios de comunicación y folletos turísticos (1\% y 5\%, respectivamente). Se observa que Internet tiene un porcentaje bastante cercano al de las agencias de viajes, pero todavía sigue siendo escaso (9\% y 10\%, respectivamente) (ver figura 9B).

MOTIVACIONES PARA REALIZAR TURISMO GASTRONÓMICO Y FACTORES DE ELECCIÓN DEL DESTINO TURÍSTICO

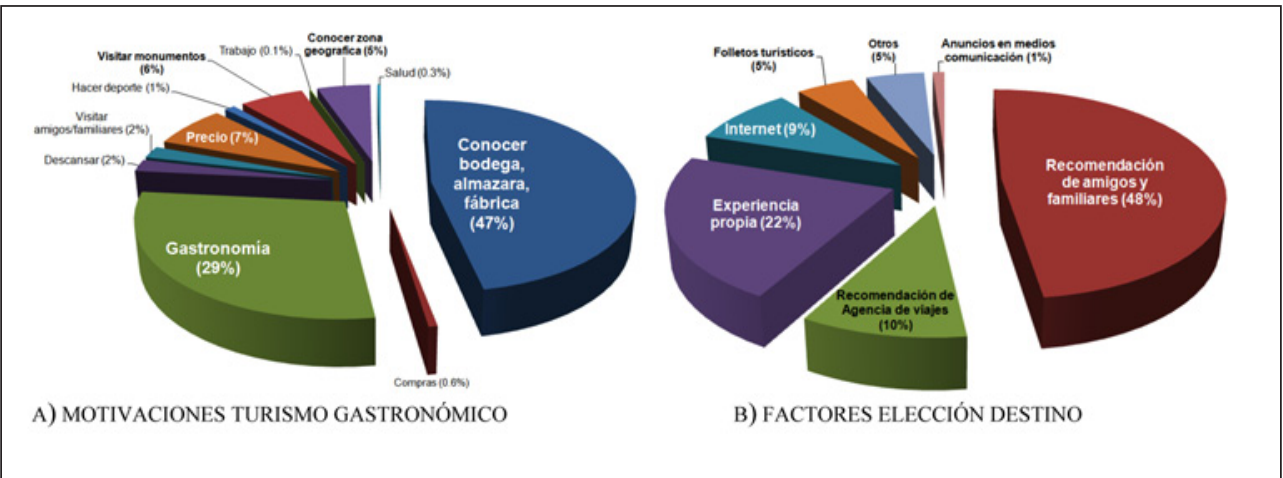

Fuente: Elaboración propia.

Por otra parte, la mayoría de los turistas gastronómicos realizan el viaje en familia (algo más del 40\%) o con su pareja (aproximadamente, un 35\%), siendo menor el número de turistas que realizan el viaje con amigos (14\%), y menor aún el número de turistas que viajan solos $(7 \%)$.

El número de bodegas, almazaras y fábricas visitadas es todavía escaso. El $61 \%$ sólo visita una de ellas, principalmente porque no están abiertas al público en las horas que sería más factible verlas. Tan sólo un 4\% visita más de tres (figura 10).

En la figura 11 se observa el porcentaje de valoración dado por el turista: el precio del viaje (gastos de alojamiento, restauración y viajes) se considera normal (52\%), el trato recibido está bien (48\%) y el entorno está bien conservado (72\%), siendo por tanto aceptable un desarrollo turístico sostenible respetando el entorno medioambiental de las zonas rurales. 
Figura 10

VISITAS REALIZADAS POR LOS TURISTAS

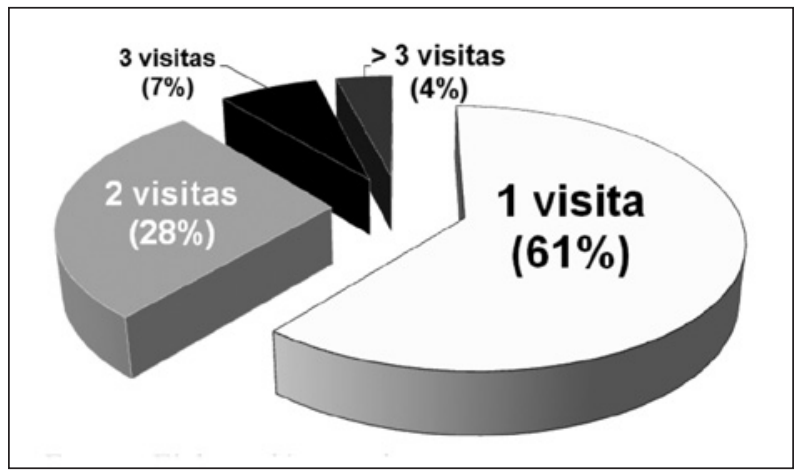

Fuente: Elaboración propia.

Figura 11

FACTORES CLAVE

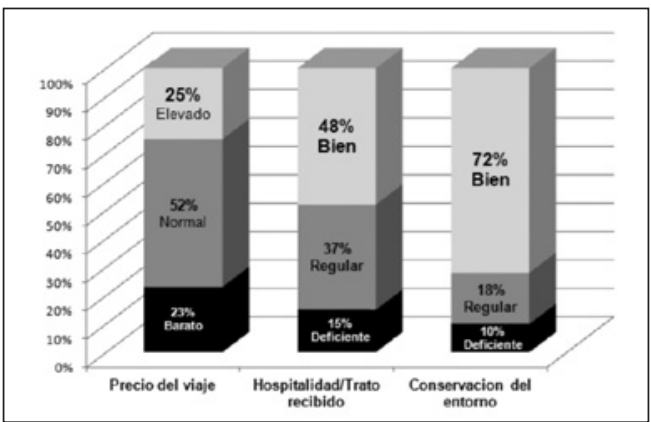

Fuente: Elaboración propia.

Figuras 12A Y 12B

SATISFACCIÓN CON LOS SERVICIOS

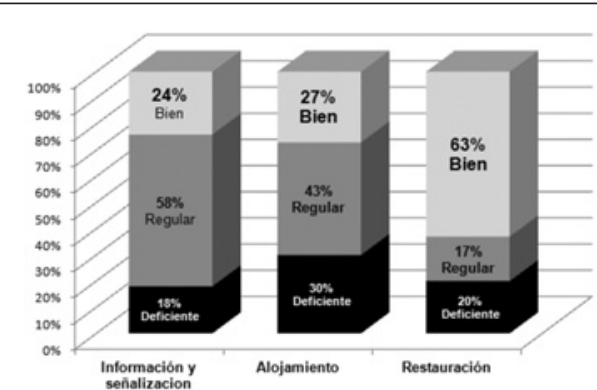

A) SERVICIOS TURÍSTICOS

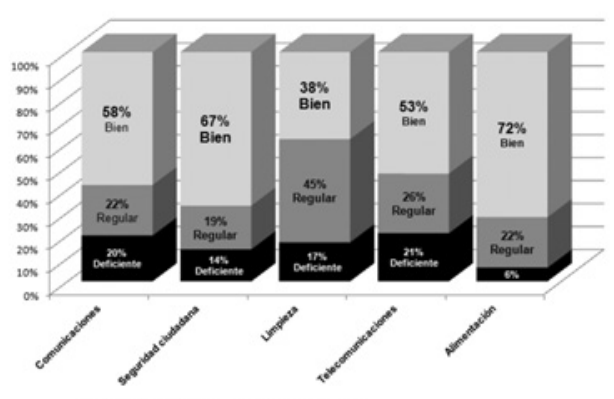

B) SERVICIOS GENERALES

Fuente: Elaboración propia. 
Respecto a las valoraciones y opiniones sobre el viaje de turismo gastronómico realizado, se ha subdividido en 5 apartados: factores clave, opinión sobre los servicios turísticos, opinión sobre las actividades complementarias y la satisfacción general con respecto a todo lo visitado y la atención recibida.

Otro apartado importante es la calificación del turista respecto a la información y señalización de la ruta gastronómica, del alojamiento y del servicio de restauración. Un alto porcentaje de ellos $(76 \%)$ considera que no está bien señalizada, es difícil acceder a algunas bodegas o almazaras, habiéndose perdido algunos turistas que realizan el viaje en su coche particular por falta de información. Respecto al alojamiento, el 73\% lo considera regularmal, por falta de profesionalidad de las personas que lo han atendido y por alojamientos rurales deficientes, mientras que la restauración obtiene una calificación muy positiva, el $63 \%$ de los turistas opinan que es buena tanto en el servicio como en la calidad de los alimentos (figura 12A), valorándolo como el mejor servicio recibido de todos los que forman el viaje $(82 \%)$, siendo el peor la falta de oferta complementaria.

Respecto a los servicios generales (figura 12B), el 58\% considera que hay buenas comunicaciones (red de carreteras, trenes y aeropuertos), la seguridad ciudadana es valorada positivamente (67\%), al igual que los productos alimenticios (72\%), necesitando mejorar la limpieza de algunas bodegas y almazaras, así como algunos núcleos rurales (62\%).

Respecto a las características del viaje, en este tipo de turismo destaca que el $66 \%$ de los encuestados no pernoctan en la zona. Una de las principales causas reside en la reducida infraestructura hotelera (pocas plazas). Muchos turistas están dispuestos a volver a la zona y su grado de satisfacción con las visitas a las almazaras es elevado. También resulta destacable la posibilidad de generar riqueza en la zona creando empleo en el sector de restauración y de artesanía, pues más del 35\% de los turistas no se han llevado ningún recuerdo (cerámica, productos típicos del lugar, etc.) al no existir tiendas especializadas de souvenir.

Para complementar el análisis descriptivo se ha realizado un análisis bivariante para establecer asociaciones entre variables, siendo las más significativas las que aparecen en el cuadro 5.

Cuadro 5

RESULTADOS DEL ANÁLISIS BIVARIANTE DE LA DEMANDA DE TURISMO GASTRONÓMICO EN ANDALUCÍA

\begin{tabular}{|l|c|c|}
\hline Variables asociadas & $\chi^{2}$ & Gl \\
\hline Bodegas, almazaras, fábricas visitadas/ satisfacción la ruta gastronómica & 24.6 & 6 \\
\hline Edad del turista /satisfacción con la ruta gastronómica & 21,7 & 8 \\
\hline Edad del turista/personas que le acompañan en el viaje & 32,3 & 6 \\
\hline Edad del turista/conocimiento de la ruta & 67,3 & 12 \\
\hline Gasto medio diario/ estado civil & 25,1 & 4 \\
\hline Gasto medio diario/ nivel de renta & 36,2 & 4 \\
\hline
\end{tabular}

$\chi^{2}$ Estadístico Chi-cuadrado. Variables relacionadas para $\alpha=0.05, \mathrm{gl}=$ grados de libertad. Fuente: Elaboración propia.

1. La cantidad de bodegas, almazaras y fábricas agroalimentarias visitadas está relacionado positivamente con el grado de satisfacción del viaje. A más bodegas, alma- 
zaras y fábricas visitadas, mayor satisfacción del turista. Un dato relevante es que la cantidad de establecimientos abiertos al público en las rutas gastronómicas analizadas es escaso, y disminuye los fines de semana y días festivos. Aunque existen diferencias entre productos gastronómicos, la cantidad de bodegas abiertas es superior a la cantidad de almazaras y fábricas agroalimentarias. Esto explica el hecho contrastado de que haya más enoturistas que turistas gastronómicos de las otras modalidades. Asimismo, se puede extraer la consecuencia de que la oferta gastronómica de la zona no satisface adecuadamente la actual demanda y, por tanto, es factible que la demanda se desvíe a otros destinos gastronómicos fuera de la zona.

2. Las variables edad del turista y conocimiento de la ruta están relacionadas. Los turistas más jóvenes encontraron la ruta a través de Internet, mientras que los enoturistas de más edad conocieron la ruta a través de amigos y familiares o de agencias de viajes (medios más tradicionales de información).

3. El nivel de renta y el gasto medio realizado en este viaje están relacionados positivamente. Las personas con mayor nivel de renta gastaron más por término medio, siendo la principal partida del gasto la compra de productos relacionados con la ruta, vino en enoturismo, aceite en oleoturismo y jamón.

4. Se debe incentivar la creación de más actividades complementarias (festivales culturales, gastronómicos), pues el destinatario mayoritario es el turista de edad madura. Esto puede generar más ingresos para la zona, siempre que se acompañe de mayor oferta de plazas hoteleras y casas rurales.

5. Es necesario un aumento de la inversión en promoción de estos destinos turísticos.

6. Se observa que las rutas del vino son más conocidas que el resto de los demás productos gastronómicos como el aceite o el jamón. El gasto medio es más elevado, debido a que los turistas visitan varias bodegas y compran diversos productos, siendo también la renta media más elevada en los enoturistas que los oleoturistas.

Cuadro 6

RESULTADOS DEL ANÁLISIS BIVARIANTE DE LA OFERTA DE TURISMO GASTRONÓMICO EN ANDALUCÍA

\begin{tabular}{|l|c|c|}
\hline Variables asociadas & $\chi^{2}$ & $\mathrm{Gl}$ \\
\hline $\mathrm{N}^{\circ}$ de trabajadores (almazara /bodegas)/implicación en la ruta & 35,8 & 12 \\
\hline Subvención/mejora y adaptación & 24,1 & 6 \\
\hline Tipo de empresa/ implicación en la ruta & 22,1 & 4 \\
\hline Formación de los trabajadores/ apertura al público & 45, & 15 \\
\hline
\end{tabular}

$\chi^{2}$ Estadístico Chi-cuadrado. Variables relacionadas para $\alpha=0.05, \mathrm{gl}=$ grados de libertad. Fuente: Elaboración propia.

Los principales resultados obtenidos se pueden resumir en lo siguiente:

1. No existe una implicación fuerte de los empresarios turísticos a formar parte de la ruta gastronómica. Falta confianza y hay escepticismo sobre futuros resultados económicos factibles. Piensan que el gasto de adaptación de la almazara/bodega para ser visitada no será compensado con los ingresos que puedan percibir. 
2. Las bodegas, almazaras y fábricas con mayor número de trabajadores tienen mejor percepción de la ruta como fuente adicional de ingresos.

3. Pocas empresas no perceptoras de subvención para adaptar sus almazaras, bodegas o fábricas al turismo lo han hecho. Solo las empresas que recibieron subvención han hecho mejoras.

4. Las empresas de carácter privado que no son cooperativas son más optimistas respecto a la posibilidad de que el turismo gastronómico pueda generar rentas adicionales. Las cooperativas son las más reacias, especialmente las más antiguas y con menos trabajadores.

5. Las bodegas y almazaras que tienen trabajadores con mayor nivel de formación (o reciclan a su personal) tienen horarios de apertura al público más amplios para facilitar las visitas. Además coincide que suelen ser sociedades anónimas o limitadas y tienen gerentes de alto nivel educativo.

\section{CONCLUSIONES}

El turismo gastronómico en Andalucía crece lentamente debido a:

1. La falta de conocimiento de las rutas gastronómicas asociadas a las D.O.P. e I.G.P. Aunque los entes públicos (patronatos de turismo, diputaciones, organismos locales) y el sector privado tratan de darles publicidad, las campañas publicitarias no son tan efectivas respecto a las expectativas.

2. Algunas rutas gastronómicas asociadas al vino son muy conocidas (acaparan más del $75 \%$ de los turistas gastronómicos), seguidas de algunas rutas del aceite de oliva. Las restantes rutas gastronómicas vinculadas a otros alimentos autóctonos son prácticamente invisibles, aunque sus productos sean conocidos por los consumidores, como las rutas gastronómicas del jamón ibérico.

3. Al estar ubicadas las almazaras, bodegas y algunas fábricas de panadería y bollería en zonas rurales, sería oportuno crear una oferta complementaria de ocio para que el turista permanezca más tiempo en la zona y, por tanto, incremente su gasto medio diario generando riqueza en la comarca donde se ubica y fortaleciendo el empleo con puestos de trabajo ligados a este sector terciario.

4. Es necesario adoptar medidas para mejorar la imagen de las zonas rurales desde el fomento del turismo participativo, en el que los turistas pueden integrarse y ser partícipes de tareas, costumbres y modos de vida locales, rescatando actividades tradicionales. Esto puede servir como factor de diferenciación con el resto de los destinos competidores.

5. La oferta de turismo gastronómico está atomizada. Cada producto tiene una oferta diferenciada. Aunque compartan zona geográfica y localidades, no existen rutas gastronómicas integradas por varios productos. Ante esta situación podría ser conveniente crear un ente o consorcio de turismo que agrupe a todas las D.O.P. de Andalucía al objeto de publicitar sus actividades y opciones turísticas complementarias. Así, el turista que realice el viaje propuesto por las rutas puede conocer varios productos en un solo itinerario que integre dos o más rutas. Por ejemplo, en Córdoba la interrelación facilitaría que un turista pudiera practicar (1) el enoturismo, visitando la ruta Montilla Moriles; (2) el oleoturismo en cualquiera de sus cinco rutas del aceite de 
oliva y (3) la degustación del jamón ibérico de la D.O.P. de los Pedroches. Esto podría ofertarse en forma de paquetes turísticos de varios días de visita a olivares, dehesas y viñedos. Esta propuesta es aplicable a otras provincias y también de manera interprovincial (por ejemplo, las rutas del Condado de Huelva y de Jerez).

6. La satisfacción de los turistas gastronómicos y su disposición a repetir supone una fidelización real con un potencial publicitario que no se aprovecha suficientemente. La escasez de actividades complementarias y la existencia insuficiente de alojamientos o las deficiencias de los existentes son aspectos a mejorar en el corto plazo para facilitar la repetición sin agotar el interés turístico. Una vía puede ser la creación de actividades complementarias como festivales culturales o gastronómicos orientado a turistas de edad madura, con niveles de renta medio-altos. También puede ser interesante la creación de museos del aceite de oliva en algunas D.O.P. donde se explique el proceso de fabricación del producto, se muestren las distintas variedades agroalimentarias de la zona y se puedan degustar los distintos aceites producidos en la comarca.

7. Muchas de las D.O.P. e I.G.P. de Andalucía se encuentran ubicadas en comarcas cercanas a Sierra Morena o a las Sierras Subbéticas, Sierra de Cazorla o Parques Naturales, contando con un gran potencial de turistas que visitan esa zona por otros motivos (rural, cinegético, etc.), factores que se podían aprovechar para desarrollar una oferta complementaria de ocio respecto al turismo gastronómico.

Andalucía se encuentra en un sitio geográficamente estratégico, por ser el puente de Unión entre África y Europa (siendo un potencial mercado receptor de turistas internacionales), cuenta con una buena red de vías de comunicación (carreteras, aeropuertos y líneas de tren) lo que posibilita el fácil acceso y una serie de productos alimentarios de un calidad excelente, reconocidos y premiados a nivel internacional (vinos, aceites de oliva, frutas, jamones, dulces) que pueden ayudar a incrementar el turismo, especialmente el gastronómico. Pero hace falta una concienciación por parte de empresas locales, bodegas y almazaras de que es necesario invertir para poder dar un servicio de calidad al cliente, este servicio podría incluir desde la formación (guías expertos que expliquen el proceso de elaboración del producto) hasta la inversión en infraestructuras (transformación de las bodegas y almazaras para ser visitadas por grupos organizados de turistas). Es necesario también, que los entes públicos apoyen dichas iniciativas, concediendo subvenciones para facilitar adaptación de los establecimientos visitables por los turistas a lo largo de las rutas y favoreciendo la publicidad de las rutas. Es por tanto, si se desea un crecimiento sostenible del turismo gastronómico, un trabajo conjunto (de entes públicos, privados) que repercutirá en la mejora de la imagen de las comarcas incluidas y en la creación de riqueza para las mismas.

\section{BIBLIOGRAFÍA}

ARMESTO, X. A. y GÓMEZ, B. (2004): «Productos agroalimentarios de calidad, turismo y desarrollo local: el caso del Priorat». Cuadernos Geográficos, n ${ }^{\circ} 34,83-94$.

BARRERA, E. (2006): «Rutas Alimentarías. Estrategias culturales de desarrollo territorial». Patrimonio Cultural y Turismo. $\mathrm{n}^{\mathrm{o}}$ 15. Itinerarios culturales y rutas del patrimonio. CONACULTA. México. 
BELL, C. y ARRANZ, A. (2011). «El turismo y el desarrollo rural en los parques naturales: El caso del Parque Natural de Grazalema (Cádiz-Málaga)». Spanish Journal of Rural Development, $\mathrm{n}^{\mathrm{o}} 2$, pp. 1-22.

BEVERLAND, M. (1988): «Wine Tourism in New Zealand - Maybe the Industry has got it right». International Journal of Wine Marketing, nº 10 (2), 24-33.

BLANCO, M. y RIVEROS, H. (2004): «Las rutas alimentarias una herramienta para valorizar productos de las agroindustrias rurales. El caso de la Ruta del Queso Turrialba (Costa Rica)», Touluca: Congreso Agroindustria Rural y Territorio-ARTE-, Toluca (México).

BRUWER, J. (2003): «South Africa Wine Routes: Some Perspectives on the Wine Tourism Industry's Structural Dimensions and Wine Tourism Product». Tourism Management, $\mathrm{n}^{\mathbf{0}}$ 24, 423-435.

CLEMENTE, J.S., RODRIGUEZ, E. y BUYTRAGO J.M.(2010): «Análisis del mercado potencial enoturístico en Valencia». Papers de turisme, n 47-48, 92-108.

CONSEJERÍA DE MEDIO AMBIENTE DE LA JUNTA DE ANDALUCIA. (2011): Datos Básicos de Medio Ambiente en Andalucía. Edición 2011, Sevilla.

EGAN, D. y BELL, A. (2002): «Chilean Wines: A Successful Image». International Journal of Wine Marketing, $\mathrm{n}^{\circ}$ 14(2), 33-42.

ELIAS, L. V. (2006): «El turismo del vino. Otra experiencia de ocio». Documentos de Estudios de Ocio, 30, Universidad de Deusto, Bilbao.

ESPEJEL, J.; FANDOS, C. y FLAVIÁN, C. (2011): «Antecedents of consumer commitment to a PDO wine: an empirical analysis of Spanish consumers». Journal of wine research, $n^{\circ} 22(2), 205-226$.

EVERETT, S. y AITCHISON, C. (2008): «The role of food tourism in sustaining Regional identity: a Case study of Cornwall, South West England. Antecedents of consumer commitment to a PDO wine: an empirical analysis of Spanish consumers». Journal Journal of Sustanaible Tourism, $\mathrm{n}^{\circ}$ 16(2), 150-167.

FEO, F. (2005): «Turismo gastronómico en Asturias». Cuadernos de Turismo, nº 15, 77-96.

FUENTES, R. (1995): «Análisis de las principales características de la demanda de turismo rural en España». Estudios Turísticos, n 127, 19-52.

GETZ, D. y BROWN, G. (2006): «Critical Success Factors for Wine Tourism Regions: A Demand Analysis». Tourism Management, $\mathrm{n}^{\circ} 27,146-158$.

GILBERT, D. C. (1992): «Touristic Development of a Viticultural Regions of Spain». International Journal of Wine Marketing, $\mathrm{n}^{\circ}$ 4(2), 25-32.

GONZÁLEZ, M.E. (2011): «Una propuesta para desarrollar turismo rural en los municipios de Zacatecas México. Las rutas agro-culturales». Revista Pasos, nº 9 (1), 119-145.

INSTITUTO NACIONAL DE ESTADÍSTICA - INE (2012): Encuesta de ocupación en alojamientos de turismo rural. http://www.ine.es/inebase.

KEANE, M. y QUINN, J. (1990): Rural Development and Rural Tourism, Social Sciences Research Centre Report, University College Galway, Galway.

LOPEZ, J.A. (2010): «Posibilidades de desarrollo del enoturismo en la Denominación de Origen Jerez-Xerry-Sherry y manzanilla de Sanlucar de Barrameda y vinagre de Jerez». Boletín de la Asociación de Geógrafos españoles, n 53, 21-41.

MÁRQUEZ, A. M. y. HERNÁNDEZ, M. J. (2001): «Cooperación y sociedades cooperativas: el caso de la Denominación de Origen Sierra Mágina». Revista de Estudios Cooperativos, Revesco, $\mathrm{n}^{\circ}$ 74, 123-149. 
MILLÁN, G. y MELIÁN, A. (2010): «El papel de las cooperativas en el turismo rural. Nuevas oportunidades para el desarrollo». Lider, n 11/15, 77-106.

MINISTERIO DE AGRICULTURA, ALIMENTACIÓN Y MEDIO AMBIENTE (2012): (http://www.magrama.gob.es/es/alimentacion/temas/calidad-agroalimentaria/calidaddiferenciada/dop, consultada 29-02-2012).

MONTOYA, T.(2003): «La gastronomía tradicional en el turismo rural»; en Martinez, M. (2003):Historia de la alimentación rural y tradicional : recetario de Almería, Instituto de Estudios Almerienses, Almeria.

OLIVEIRA, S. (2011): «La gastronomía como atractivo turístico primario de un destino. El turismo gastronómico en Mealhada. Portugal». Estudios y Perspectivas en Turismo, ${ }^{\circ}$ 20, 738-752.

PETERS, G. (1997). American winescapes: the cultural landscapes of America's wine country. Boulder: Westview Press/Harpers Collins.

PULIDO, J.I. y CÁRDENAS J.P. (2011): «El turismo rural en España. Orientaciones estratégicas para una tipología aún en desarrollo». Boletín de la Asociación de Geógrafos españoles, $\mathrm{n}^{\circ} 56,155-176$.

RASCH, L y GRETZEL, U. (2008): «Wineries' Involvement in Promoting Tourism Online: The case of Texas». Pasos: Revista de turismo y patrimonio cultural, nº 6(2), 317-326

RÁTZ, T. y PUCZKÓ, L. (1998): Turismo rural y desarrollo sostenible en Hungría, Actas Conferencia Internacional Rural Tourism Managment: Sustainable options, Escocia, pp. 22.

SISTEMA DE INFORMACIÓN MULTITERRITORIAL DE ANDALUCÍA - SIMA (2010): Web: http://www.juntadeandalucia.es:9002/sima/index2.htm (consultada el 19-01-2012).

SWARBROOKE, J. (1996): Towards the development of Sustainable Rural Turism in Eastern Euro, In G. Richards(ed): Tourism in Central and eastern Europe: Educating for Quality, Atlas, Tilbug. pp. 137-163

SZIVAS, E. (1999): «The Development of Wine Tourism in Hungary». International Journal of Wine Marketing, $\mathrm{n}^{\mathrm{o}} 11(2), 7-17$.

TRIGO, L. G. (1993): Turismo e qualidade: tendências contemporâneas. Papirus, São Paulo. 
